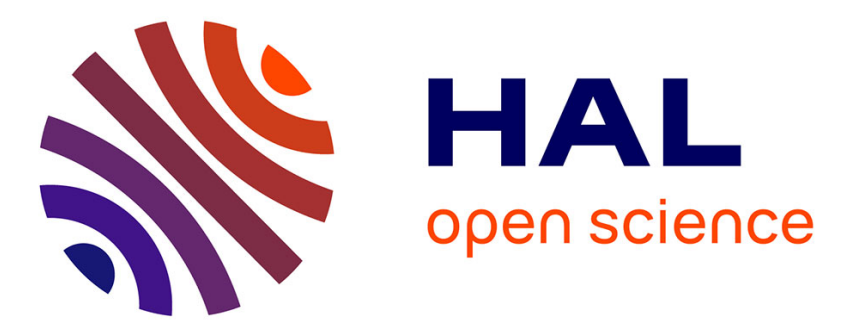

\title{
On the use of the geometric mean approximation in estimating the effective hygro-elastic behaviour of fiber-reinforced composites
}

\author{
Sylvain Fréour, Frédéric Jacquemin, Ronald Guillén
}

\section{To cite this version:}

Sylvain Fréour, Frédéric Jacquemin, Ronald Guillén. On the use of the geometric mean approximation in estimating the effective hygro-elastic behaviour of fiber-reinforced composites. Journal of Materials Science, 2007, 42 (17), pp.7537-7543. 10.1007/s10853-007-1621-y . hal-01007162

\section{HAL Id: hal-01007162 https://hal.science/hal-01007162}

Submitted on 16 Jun 2014

HAL is a multi-disciplinary open access archive for the deposit and dissemination of scientific research documents, whether they are published or not. The documents may come from teaching and research institutions in France or abroad, or from public or private research centers.
L'archive ouverte pluridisciplinaire HAL, est destinée au dépôt et à la diffusion de documents scientifiques de niveau recherche, publiés ou non, émanant des établissements d'enseignement et de recherche français ou étrangers, des laboratoires publics ou privés. 


\title{
On the use of the geometric mean approximation in estimating the effective hygro-elastic behavior of fiber-reinforced composites
}

\author{
Sylvain Fréour · Frederic Jacquemin • \\ Ronald Guillén
}

\begin{abstract}
A geometric averaging isemployed in a scale transition model dedicated to determining the effective hygro-elastic macroscopic properties of a fiber-reinforced composites from the properties of its constituents (i.e., the fiber and the matrix), for the first time. Calculations of macroscopic and local stresses due to hygroscopic loads are also carried out. Numerical computations performed according to the geometric mean are compared to the corresponding predictions given by the arithmetic average, classically used in the field of micro-mechanical modeling.
\end{abstract}

\section{Introduction}

The problem of determining the effective macroscopic properties of a composite structure from tensor quantities describing the heterogeneous microscopic properties of the fiber and matrix has a long history and rich literature. Actually, many numerical models have been used to achieve these computations: Special interest has been given to the relationship between macroscopic and microscopic elastic constants [1-9], but the case of the coefficients of moisture expansion has been studied too [8-10]. These models differ from one to another in the constitutive relations linking the microscopic and macroscopic properties. Nevertheless, the averaging procedure involved during the

S. Fréour F. Jacquemin R. Guillén Institut de Recherche en Ge' nie Civil et Mécanique (UMR CNRS 6183), IUT de Saint-Nazaire, Université de Nantes, Ecole Centrale de Nantes CRTT, 37 Boulevard de l'Université,BP 406, 44602 Saint-Nazaire cedex, France

e-mail: sylvain.freour@univ-nantes.fr homogenization process required to achieve the computation of the effective macroscopic quantities is identical in any of them: the classical arithmetic mean is used. More recently, the idea of replacing arithmetic averages by geometric averages was proposed by Morawiec [11]. This new solution, historically introduced in particular cases by Aleksandrov and Aisenberg [12] is based on the condition of the commutation of inversion and averaging operations that is one fundamental property observed in practice in materials sciences. One new scale transition model, the Bulk Path Geo (BPG) was recently built on this constitutive assumption [13, 14]. Numerical computations of the effective elastic behavior of metallic polycrystals were achieved. It was shown by the authors, that Young's modulus predicted by the BPG approximation was very close to the numerical values provided by the EshelbyKröner model [6, 7] using arithmetic averages classically considered as a reference for the rigorous modeling of macroscopic elastic properties in polycrystals. Nevertheless, the BPG framework remains independent from any other model. Thus, the closeness of its predictions with those of others models in some specific cases does not prove that geometric averages would, in any case, yield results similar to the prediction obtained through, for example the more classical arithmetic averages. Until now, only the type of assumed interactions between microscopic constituents and the macroscopic structure, which generally depend on the fundamental hypotheses of each model, was considered to play a role in such studies: the effect of the averaging method used in order to perform numerical computations was assumed to be negligible. In the present work, Eshelby-Kröner Self-Consistent scale transition models involving either arithmetic averages or geometric averages will be used to predict both the mechanical elastic properties and the coefficients of moisture expansion 
(CME) of fiber-reinforced composites. Examples of macroscopic and local stresses states for multi-directionnal laminates submitted to hygroscopic loads, deduced from the formerly estimated homogenized stiffnesses and CME, will be given also. The results obtained on the basis of the two different types of averaging for the mechanical elastic properties and the CME will be compared and discussed.

\section{Arithmetic and geometric averages}

Macroscopic quantities can be obtained from scale transition model homogenization procedures using volumeweighted averages (that in fact replace volume integrals that would require Finite Elements Methods instead). This assertion was historically, rigorously demonstrated by Hill in [15]. According to Kocks et al. [16], "when the average is meant to represent a physical property of the aggregate", (i.e., of the macroscopic behavior of the material), "it is crucial to decide which is the correct averaging procedure". Unfortunately, this issue is not extensively developed in ref. [16]. Actually, if the classical arithmetic average is most of the time employed, in order to achieve such calculations, a geometric average was also considered as an alternate interesting procedure, after the publication of Aleksandrov and Aisenberg proposal in 1966 [12]. On the one hand, the geometric mean of a set of positive data is defined as the $n^{\text {th }}$ root of the product of all the members of the set, where $\mathrm{n}$ is the number of members. On the other hand, in mathematics and statistics, the arithmetic mean (or simply the mean) of a list of numbers is the sum of all the members of the list divided by the number of items in the list. Empirically, as stated by Hill in [3], arithmetic or geometric averages of the Voigt and Reuss overall properties suggest themselves as good approximations. For Young's modulus (E), as an example, the Geometric Average $\mathrm{E}_{\mathrm{GA}}$ of the moduli according to the Reuss $\left(E_{R}\right)$ and Voigt $\left(E_{V}\right)$ models is defined as $E_{G A}=\sqrt{E_{R} E_{V}}$, whereas the corresponding Arithmetic Average $E_{A A}$ is: $E_{A A}=\frac{E_{R}+E_{v}}{2}$.

In statistics, given a set of data, $X=\left\{x^{1}, x^{2}, \ldots, x^{1}, \ldots, x^{n}\right\}$ and corresponding weights, $W=\left\{w^{1}, w^{2}, \ldots, w^{i}, \ldots, w^{n}\right\}$, the weighted geometric (respectively, arithmetic) mean $\left\langle\mathrm{X}^{\alpha}\right\rangle_{\mathrm{GA}}^{\alpha=1,2, \ldots, \mathrm{i}, \ldots, \mathrm{n}}$ (respectively, $\left\langle\mathrm{X}^{\alpha}\right\rangle_{\mathrm{AA}}^{\alpha=1,2, \ldots, \mathrm{i}, \ldots, \mathrm{n}}$ ) is calculated as:

$$
\begin{aligned}
& \left.\left\langle\mathrm{X}^{\alpha}\right\rangle_{\mathrm{GA}}^{\alpha=1,2, \ldots, \mathrm{i}, \ldots, \mathrm{n}}=\prod_{\alpha=1}^{\mathrm{n}} \mathrm{x}^{\alpha^{\mathrm{w}^{\alpha}}}\right)^{1 /\left(\sum_{\alpha=1}^{\mathrm{n}} \mathrm{w}^{\alpha}\right)} \\
& \left\langle\mathrm{X}^{\alpha}\right\rangle_{\mathrm{AA}}^{\alpha=1,2, \ldots, \mathrm{i}, \ldots, \mathrm{n}}=\left(\frac{1}{\sum_{\alpha=1}^{\mathrm{n}} \mathrm{w}^{\alpha}}\right) \sum_{\alpha=1}^{\mathrm{n}} \mathrm{x}^{\alpha} \mathrm{w}^{\alpha}
\end{aligned}
$$

Scale transition models are based on a multi-scale representation of materials. Let us, in the present work, consider a fiber-reinforced, two-constituents composite structure. In the case of such a composite materials, for instance, a two-scale model is sufficient:

- The properties and mechanical states of either the resin or its reinforcements are respectively indicated by the superscripts ${ }^{\mathrm{m}}$ and ${ }^{\mathrm{f}}$. These constituents define the socalled "pseudo-macroscopic" scale of the material [17].

- Homogenization operations performed over its aforementioned constituents are assumed to provide the effective behavior of the composite ply, which defines the macroscopic scale of the model. It is denoted by the superscript ${ }^{\mathrm{I}}$. This definition also enables to consider an uni-directional reinforcement at macroscopic scale, which is a satisfactorily realistic statement, compared to the present design of composite structures (except for the particular case of woven-composites).

Thus, the composite contains a volume fraction $\mathrm{v}^{\mathrm{m}}$ of matrix, presenting a tensorial property/mechanical state $\mathbf{X}^{\mathbf{m}}$. As a consequence, the material also contains a volume fraction $v^{\mathrm{f}}=1-\mathrm{v}^{\mathrm{m}}$ of reinforcing fibers, a tensorial property/mechanical state of which is $\mathbf{X}^{\mathbf{f}}$. In this particular case, the brackets $\left\langle\mathbf{X}^{\alpha}\right\rangle^{\alpha=\mathbf{f}, \mathbf{m}}$ stand for volume-weighted averages over the pseudo-macroscopic quantity $\mathbf{X}$. Let us rewrite Eqs. (1) and (2) for this particular case:

- the geometric approximation assumes that macroscopic averages can be calculated through the product of the constituent quantities powered by the volume fractions of the constituents so that the general form (1) transforms as follows:

$$
\left\langle\mathbf{X}^{\alpha}\right\rangle_{\mathbf{G A}}^{\alpha=\mathbf{f}, \mathbf{m}}=\mathbf{X}^{\mathbf{m}^{\mathrm{r}^{\mathrm{m}}}} \mathbf{X}^{\mathbf{f}^{\mathrm{r}^{\mathrm{f}}}}
$$

- whereas the arithmetic approximation assumes that tensor averages correspond to the sum of the corresponding constituent quantities, weighted by the volume fraction of the constituents so that the general form (2) transforms as follows:

$$
\left\langle\mathbf{X}^{\alpha}\right\rangle_{\mathbf{A A}}^{\alpha=\mathbf{f}, \mathbf{m}}=\mathrm{v}^{\mathrm{m}} \mathbf{X}^{\mathbf{m}}+\mathrm{v}^{\mathrm{f}} \mathbf{X}^{\mathbf{f}}
$$

In practice arithmetic averages can be calculated in any case. However, due to the volume fraction weighting through powers, the geometric average can be achieved in the cases that the considered microscopic tensors have positive components only. This condition is a strong constraint limiting the application of the geometric averages for the calculation of mechanical states, mesoscopic stresses and strains generally containing both negative and positive components. Nevertheless, as shown in [11, 13], 
physical constants like mechanical stiffnesses can always be determined using such geometric approaches, because they are positive.

\section{Estimation of macroscopic hygro-elastic properties using Eshelby-Kröner self-consistent model}

The classical Self-Consistent framework corresponding to the formalism introduced by Kröner [7] and Eshelby [6] is based on the mechanical treatment of the interactions between ellipsoidal heterogeneous inclusions embedded in an infinite medium.

The implicit relation used for the calculation of the macroscopic stiffness tensor $\mathbf{L}^{\mathbf{I}}$ is very classical. The interested reader can refer to $[9,16]$, where an extensive demonstration is given and leads to:

$\mathbf{L}^{\mathbf{I}}=\left\langle\left(\mathbf{L}^{\alpha}+\mathbf{L}^{\mathbf{I}}: \mathbf{R}^{\mathbf{I}}\right)^{-1}:\left(\mathbf{L}^{\mathbf{I}}+\mathbf{L}^{\mathbf{I}}: \mathbf{R}^{\mathbf{I}}\right): \mathbf{L}^{\alpha}\right\rangle^{\alpha=f, m}$

where $\mathbf{L}^{\alpha}$ is the elastic stiffness of the constituent $\alpha$, i.e., the fiber or the matrix. $\mathbf{R}^{\mathrm{I}}$ represents the so-called reaction tensor that expresses the elastic interactions due to the morphology assumed for the elementary constituents of the composite material. It satisfies:

$\mathbf{R}^{\mathbf{I}}=\left(\mathbf{L}^{\mathbf{I}^{-1}}-\mathbf{E}^{\mathbf{I}}\right): \mathbf{E}^{\mathbf{I}^{-1}}$

Thus, the average macroscopic elastic properties $\mathbf{L}^{\mathrm{I}}$ of the composite are related to the morphology assumed for elementary inclusions, through Morris' tensor $\mathbf{E}^{\mathbf{I}}$. Spherical inclusions only were initially considered by Morris [18]. In the case, when ellipsoidal-shaped inclusions have to be taken into account, the following general form enables the calculation of the components of this tensor (see the works of Asaro and Barnett [19] or Kocks et al. [16]):

$\left\{\begin{array}{l}\mathrm{E}_{\mathrm{ijkl}}^{\mathrm{I}}=\frac{1}{4 \pi} \int_{0}^{\pi} \sin \theta \mathrm{d} \theta \int_{0}^{2 \pi} \gamma_{\mathrm{ikjl}} \mathrm{d} \phi \\ \gamma_{\mathrm{ikjl}}=\mathrm{K}_{\mathrm{ik}}^{-1}(\xi) \xi_{\mathrm{j}} \xi_{1}\end{array}\right.$

In the case of an orthotropic macroscopic symmetry, the components $\mathrm{K}_{\mathrm{jp}}(\xi)$ were given by Kröner [7]: with

$\xi_{1}=\frac{\sin \theta \cos \phi}{\mathrm{a}_{1}}, \xi_{2}=\frac{\sin \theta \sin \phi}{\mathrm{a}_{2}}, \xi_{3}=\frac{\cos \theta}{\mathrm{a}_{3}}$

where $2 a_{1}, 2 a_{2}, 2 a_{3}$ are the lengths of the principal axes of the ellipsoid, assumed to be respectively parallel to the longitudinal, transverse and normal directions of the sample reference frame.

Within Kröner [7] and Eshelby [6] self-consistent framework, the hygroscopic dilatation generated by a moisture content increment $\Delta \mathrm{C}^{\alpha}$ is treated as a transformation strain exactly like the thermal dilatation occurring after a temperature increment (that last case was extensively discussed in the literature, see for example Kocks et al. [16]). Introducing $\beta$ for denoting CME, it was demonstrated by Jacquemin and al. in [9] that the macroscopic CME $\beta^{\mathrm{I}}$ satisfy:

$$
\begin{aligned}
\beta^{\mathbf{I}}= & \frac{\Delta \mathrm{C}^{\mathrm{m}}}{\Delta \mathbf{C}^{\mathrm{I}}}\left(\left\langle\left(\mathbf{L}^{\alpha}+\mathbf{L}^{\mathbf{I}}: \mathbf{R}^{\mathbf{I}}\right)^{-1}\right\rangle^{\alpha=\mathrm{f}, \mathrm{m}}\right)^{-1}: \\
& \left\langle\left(\mathbf{L}^{\alpha}+\mathbf{L}^{\mathbf{I}}: \mathbf{R}^{\mathbf{I}}\right)^{-1}: \mathbf{L}^{\alpha} \cdot \beta^{\alpha}\right\rangle^{\alpha=\mathrm{f}, \mathrm{m}}
\end{aligned}
$$

\section{Numerical applications}

Computations of the macroscopic elastic stiffnesses of composite structures were performed following the formalism described in Sects. 'Arithmetic and geometric averages' and 'Estimation of macroscopic hygro-elastic properties using Eshelby-Kröner self-consistent model', using either the arithmetic or the geometric averages. Two materials were successively considered: a carbon/epoxy composite T300/5208 and a Metal Matrix Composite (MMC) $\mathrm{Al} / \mathrm{SiC}$. The behavior of each composite is governed by its constituents, i.e., the properties of the fibers, the surrounding matrix and the relative amount of the fibers and matrix in the material. Calculations were performed assuming the initial local elastic properties listed in $\mathrm{Ta}$ ble 1 , and a volume fraction of $40 \%$ for the matrix ( $\mathrm{Al}$ or N5208). The macroscopic stiffnesses $\mathbf{L}^{\mathbf{I}}$ obtained for unidirectionally reinforced composites are summarized in Table 2 (in order to take into account the proper fiber microstructure of the material, the following values were taken for the length of the semi-axis of the inclusions:

$$
\mathbf{K}=\left[\begin{array}{ccc}
\mathrm{L}_{11}^{\mathrm{I}} \xi_{1}^{2}+\mathrm{L}_{66}^{\mathrm{I}} \xi_{2}^{2}+\mathrm{L}_{55}^{\mathrm{I}} \xi_{3}^{2} & \left(\mathrm{~L}_{12}^{\mathrm{I}}+\mathrm{L}_{66}^{\mathrm{I}}\right) \xi_{1} \xi_{2} & \left(\mathrm{~L}_{13}^{\mathrm{I}}+\mathrm{L}_{55}^{\mathrm{I}}\right) \xi_{1} \xi_{2} \\
\left(\mathrm{~L}_{12}^{\mathrm{I}}+\mathrm{L}_{66}^{\mathrm{I}}\right) \xi_{1} \xi_{2} & \mathrm{~L}_{66}^{\mathrm{I}} \xi_{1}^{2}+\mathrm{L}_{22}^{\mathrm{I}} \xi_{2}^{2}+\mathrm{L}_{44}^{\mathrm{I}} \xi_{3}^{2} & \left(\mathrm{~L}_{23}^{\mathrm{I}}+\mathrm{L}_{44}^{\mathrm{I}}\right) \xi_{2} \xi_{3} \\
\left(\mathrm{~L}_{13}^{\mathrm{I}}+\mathrm{L}_{55}^{\mathrm{I}}\right) \xi_{1} \xi_{2} & \left(\mathrm{~L}_{23}^{\mathrm{I}}+\mathrm{L}_{44}^{\mathrm{I}}\right) \xi_{2} \xi_{3} & \mathrm{~L}_{55}^{\mathrm{I}} \xi_{1}^{2}+\mathrm{L}_{44}^{\mathrm{I}} \xi_{2}^{2}+\mathrm{L}_{33}^{\mathrm{I}} \xi_{3}^{2}
\end{array}\right]
$$


Table 1 Mechanical properties of the constituents of the studied composites

\begin{tabular}{|c|c|c|c|c|c|}
\hline & $\mathrm{E}_{1}[\mathrm{GPa}]$ & $\mathrm{E}_{2}, \mathrm{E}_{3}[\mathrm{GPa}]$ & $v_{12}, v_{13}$ & $\mathrm{G}_{23}[\mathrm{GPa}]$ & $\mathrm{G}_{12}[\mathrm{GPa}]$ \\
\hline T300 fibers [20] & 230 & 15 & 0.2 & 7 & 15 \\
\hline N 5208 epoxy matrix [21] & 4.5 & 4.5 & 0.4 & 1.6 & 1.6 \\
\hline $\mathrm{SiC}$ & 402.1 & 402.1 & 0.18 & 170.1 & 170.1 \\
\hline Aluminum & 71.0 & 71.0 & 0.35 & 26.4 & 26.4 \\
\hline
\end{tabular}

Table 2 Mechanical properties at macroscopic scale deduced from computations, in uni-directionally reinforced composites

\begin{tabular}{lllcccc}
\hline & Composite & $\mathrm{E}_{1}[\mathrm{GPa}]$ & $\mathrm{E}_{2}, \mathrm{E}_{3}[\mathrm{GPa}]$ & $v_{12}, v_{13}$ & $\mathrm{G}_{23}[\mathrm{GPa}]$ & $\mathrm{G}_{12}[\mathrm{GPa}]$ \\
\hline Arithmetic average & $\mathrm{T} 300 / 5208$ & 139.7 & 10.1 & 0.27 & 3.3 & 7.0 \\
$\quad$ (Eshelby-Kröner model) & $\mathrm{Al} / \mathrm{SiC}$ & 264.7 & 195.3 & 0.24 & 72 & 83 \\
Geometric average & $\mathrm{T} 300 / 5208$ & 60.5 & 9.4 & 0.27 & 3.0 & 4.5 \\
$\quad$ (Eshelby-Kröner model) & $\mathrm{Al} / \mathrm{SiC}$ & 221.0 & 171.4 & 0.24 & 62 & 65.2 \\
Relative deviation: $\Delta \mathrm{a}=\frac{\mathrm{a}_{\text {geo }}-\mathrm{a}_{\text {ari }}}{\mathrm{a}_{\text {ari }}}$ & $\mathrm{T} 300 / 5208$ & -0.57 & -0.07 & 0.00 & -0.10 & -0.36 \\
& $\mathrm{Al} / \mathrm{SiC}$ & -0.17 & -0.12 & 0.00 & -0.13 & -0.21 \\
\hline
\end{tabular}

$\mathrm{a}_{2}=\mathrm{a}_{3}=1$, and $\mathrm{a}_{1} \rightarrow \infty$, where the subscripts $1,2,3$ respectively stand for the longitudinal, transverse and normal directions of the fibers). In order to check the influence of the assumed morphology of the inclusions, calculations were performed for a longitudinal length $a_{1}$ of the semi-axis varying from 1 to 50 . Figure 1 displays the
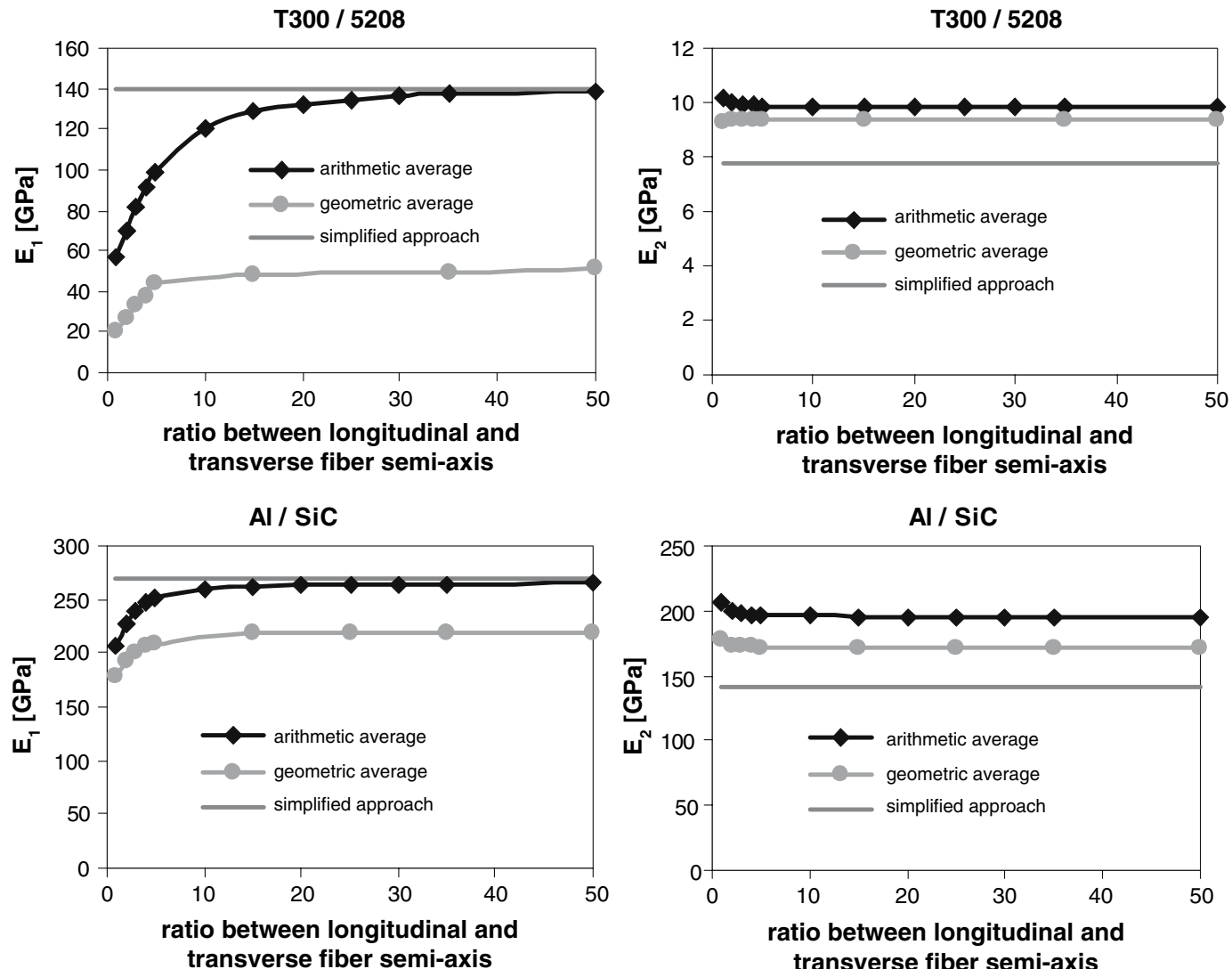

Fig. 1 Longitudinal and transverse macroscopic Young's moduli as a function of the geometry assumed for the constituents. Comparison between geometric and arithmetic averages 
evolution of both the longitudinal and transverse Young's modulus for the carbon epoxy composite and the metal matrix composite, as a function of the averaging type and the inclusion geometry. Comparison with the moduli calculated through the classical "simplified approach": $\left\{\begin{array}{l}\mathrm{E}_{1}=\mathrm{v}^{\mathrm{f}} \mathrm{E}_{1}^{\mathrm{f}}+\mathrm{v}^{\mathrm{m}} \mathrm{E}^{\mathrm{m}} \\ \frac{1}{\mathrm{E}_{2}}=\frac{\mathrm{v}^{\mathrm{f}}}{\mathrm{E}^{\mathrm{f}}}+\frac{\mathrm{v}^{\mathrm{m}}}{\mathrm{E}^{\mathrm{m}}}\end{array}\right.$ are provided on the same figure. Table 4 gives the predicted macroscopic CME of T300/ 5208 calculated according to Eq. (10), taking into account the properties of the constituents listed in Tables 1 and 3, and assuming the following ratio between the moisture content in the epoxy matrix and the structure: $\frac{\Delta \mathrm{C}^{\mathrm{m}}}{\Delta \mathrm{C}^{\mathrm{r}}}=3.33$. The calculation of this ratio, corresponding to a perfect adhesion between the fibers and the matrix (i.e., the moisture is concentrated in the matrix only), is detailed by Loos and Springer in [22], see also [9, 10] for numerical application to T300/5208. The CME predicted by EshelbyKröner are compared to the corresponding Tsai-Hahn estimations in Table 4 (Tsai-Hahn model is extensively described in [8]).

\section{Consequences for predicting macroscopic and local stresses concentrations in fiber-reinforced laminates}

Thin laminated composite pipes composed of uni-directionally reinforced carbon-epoxy plies oriented alternatively and symmetrically at +55 and $-55^{\circ}$ versus the longitudinal axis (denoted $\left[55^{\circ} /-55^{\circ}\right]_{\mathrm{s}}$ ), made up of T300/ 5208, with thickness $4 \mathrm{~mm}$ (so that a macroscopic stress state holds within the whole structure) are studied. The material, initially dry, is then exposed to an ambient fluid at a boundary concentration $c_{0}=1.5 \%$ for the determination

Table 3 CME for the constituents of T300/5208 composite

\begin{tabular}{lll}
\hline & $\beta_{11}$ & $\beta_{22}, \beta_{33}$ \\
\hline T300 fibers [20] & 0 & 0 \\
N 5208 epoxy matrix [21] & 0.6 & 0.6
\end{tabular}

Table 4 Macroscopic CME estimated in uni-directionally reinforced T300/5208 composite

\begin{tabular}{lll}
\hline & $\beta_{11}$ & $\beta_{22}, \beta_{33}$ \\
\hline Tsai-Hahn model & 0.026 & 1.110 \\
Arithmetic average & 0.035 & 1.026 \\
Geometric average & 0.086 & 1.038 \\
Relative deviation & 1.46 & 0.01 \\
$\quad$ Eshelby-Kröner model) $\Delta \mathrm{a}=\frac{\mathrm{a}_{\mathrm{geo}}-\mathrm{a}_{\text {ari }}}{\mathrm{a}_{\text {ari }}}$ & & \\
\hline
\end{tabular}

of the macroscopic stresses at the equilibrium state. The closed-form formalism used in order to determine the mechanical stresses $\sigma^{\mathbf{I}}$ and strains $\varepsilon^{\mathbf{I}}$ in each ply of the structure is described by Jacquemin and Vautrin [23]. The macroscopic stress states calculated in the central ply of the $\left[55^{\circ} /-55^{\circ}\right]_{\mathrm{s}}$ structure, from the hygro-elastic properties formerly deduced from the both studied averaging procedures (see Sect. 'Numerical applications' above) are displayed on Table 5, where the corresponding strength ratio estimated using a quadratic generalized Von Mises criterion is also given (the macroscopic strength data are available in [21]). The macroscopic stresses of the uni-directionally reinforced structure are obviously null at the equilibrium.

Starting with the macroscopic states deduced from continuum mechanics, the local stresses in both the fiber and matrix were calculated using the scale-transition relations established in [9]:

$$
\begin{aligned}
\sigma^{\alpha}= & \mathbf{L}^{\alpha}:\left(\varepsilon^{\alpha}-\beta^{\alpha} \Delta \mathbf{C}^{\alpha}\right) \\
\varepsilon^{\alpha}= & \left(\mathbf{L}^{\alpha}+\mathbf{L}^{\mathbf{I}}: \mathbf{R}^{\mathbf{I}}\right)^{-1}:\left[\left(\mathbf{L}^{\mathbf{I}}+\mathbf{L}^{\mathbf{I}}: \mathbf{R}^{\mathbf{I}}\right):\right. \\
& \left.\varepsilon^{\mathbf{I}}+\mathbf{L}^{\alpha}: \beta^{\alpha} \Delta \mathbf{C}^{\alpha}-\mathbf{L}^{\mathbf{I}}: \beta^{\mathbf{I}} \Delta \mathbf{C}^{\mathbf{I}}\right]
\end{aligned}
$$

where ${ }^{\alpha}$ stands for the subscript corresponding to the considered constituents (i.e., $\alpha=\mathrm{m}$ or $\mathrm{f}$ ).

The local stresses, determined assuming that the carbon fibers do not absorb water (i.e., $\Delta C^{f}=0$ ) are shown in Table 6.

\section{Discussion}

The comparison of macroscopic hygro-elastic behavior estimated through either the geometric or the arithmetic averaging method (see Fig. 1, Table 2 and Tables 4-6) yields the following remarkable observations:

(i) Contrary to the case, previously studied in [11], of single-phase polycrystals, geometric and arithmetic averages do not generally lead to identical macroscopic stiffness tensors and CME when multi-phase materials, such as composites, are investigated.

Table 5 Stresses [MPa] estimated in the central ply of a $\left[55^{\circ} /-55^{\circ}\right]_{\mathrm{S}} \mathrm{T} 300 / 5208$ composite at the hygroscopic equilibrium state (the superscript ${ }^{\mathrm{I}}$ stands for macroscopic quantities)

\begin{tabular}{lccccc}
\hline Average type & $\sigma_{11}^{\mathrm{I}}$ & $\sigma_{22}^{\mathrm{I}}$ & $\sigma_{12}^{\mathrm{I}}$ & $\sigma_{13}^{\mathrm{I}}=\sigma_{23}^{\mathrm{I}}=\sigma_{33}^{\mathrm{I}}$ & $\begin{array}{l}\text { Strength } \\
\text { ratio }\end{array}$ \\
\hline Arithmetic & 68.2 & -68.2 & 24.8 & 0 & 3.6 \\
Geometric & 89.0 & -89.0 & 32.4 & 0 & 2.7 \\
\hline
\end{tabular}


Table 6 Local stresses [MPa] estimated in the central ply of T300/ 5208 composites at the hygroscopic equilibrium state. The superscript ${ }^{\alpha}$ stands for pseudo-macroscopic quantities, i.e., averages over the

\begin{tabular}{|c|c|c|c|c|c|c|c|}
\hline Structure & Constituent & Average type & $\sigma_{11}^{\alpha}$ & $\sigma_{22}^{\alpha}$ & $\sigma_{12}^{\alpha}$ & $\sigma_{33}^{\alpha}$ & $\sigma_{13}^{\alpha}=\sigma_{23}^{\alpha}$ \\
\hline \multirow[t]{4}{*}{ Uni-directional } & \multirow[t]{2}{*}{ Fiber } & Arithmetic & 153.2 & 80.9 & 0 & 80.9 & 0 \\
\hline & & Geometric & 326.9 & 79 & 0 & 79 & 0 \\
\hline & \multirow[t]{2}{*}{ Matrix } & Arithmetic & -231.0 & -123.1 & 0 & -123.1 & 0 \\
\hline & & Geometric & -221.9 & -116.2 & 0 & -116.2 & 0 \\
\hline \multirow[t]{4}{*}[55^{\circ}/-55^{\circ}]{$_{S}$} & \multirow[t]{2}{*}{ Fiber } & Arithmetic & 281.7 & 4.8 & 33.8 & 85.7 & 0 \\
\hline & & Geometric & 735.6 & -21.0 & 49.8 & 85.0 & 0 \\
\hline & \multirow[t]{2}{*}{ Matrix } & Arithmetic & -253.2 & -177.8 & 9.23 & -131.3 & 0 \\
\hline & & Geometric & -246.1 & -189.6 & 17.0 & -124.1 & 0 \\
\hline
\end{tabular}

(ii) The discrepancies between the estimated values is higher along the fiber axis for the cases of both the elastic constants (cf. Table 2 and Fig. 1) and CME (cf. Table 4). Consequently, the deviation between arithmetic and geometric estimations is also closely related to the morphology assumed for the constituents.

(iii) The ratio between the longitudinal microscopic Young modulus of $\mathrm{SiC}$ and $\mathrm{Al}$ is equal to 5.7, whereas it reaches 51 when the properties of $\mathrm{T} 300$ fibers are compared to those of the N5208 matrix. Moreover, the relative deviation between the macroscopic stiffnesses estimated through the two types of averages is weaker for the metal matrix composite than in the case of the carbon epoxy composite (cf. Table 2). Consequently, according to the numerical computations, deviation between the macroscopic quantities obtained according to geometric or arithmetic averages increases with the heterogeneity of the corresponding microscopic properties. This explains why the geometric average was found to predict macroscopic elastic properties close to the estimations of the classical arithmetic average, in the case that single-phase polycrystals only were considered (see [11]), the microscopic elastic heterogeneities existing between the differently oriented grains in such polycrystal being extremely small in comparison with the heterogeneities existing between the properties of the different constituents of composite structures.

(iv) According to the literature [9] (see also Fig. 1 and Table 4 of the present study), Eshelby-Kröner selfconsistent model associated with arithmetic averages predicts macroscopic properties of composites being close to those obtained according to the classical simplified approach (for the elastic constants) or Tsai-Hahn estimates (for the CME), especially in the longitudinal direction of the structure. Figure 1 constituent $\alpha$ ( $\alpha$ should respectively be replaced by $\mathrm{m}$ or $\mathrm{f}$ in the case where the matrix or the fibers are concerned) 
of the strength ratio given in Table 5). Thus, the geometric approximation is not at all recommended for properly designing composites structures : the arithmetic mean provides a far more reliable estimation.

\section{References}

1. Reuss A (1929) Z Angw Math Mech 9:49

2. Voigt W (1928) Lehrbuch der Kristallphysik. Teubner, Leipzig/ Berlin

3. Hill R (1952) Proc Phys Soc London 65:349

4. Christensen RM (1979) Mechanics of composite materials. Wiley, New York

5. Wu CTD, Mc Cullogh RL (1977) In: Holister GS (ed) Developments in composite materials. Applied Science, London

6. Eshelby JD (1957) Proc Roy Soc A241:376

7. Kröner E (1958) Zeitschrift für Physik 151:504

8. Tsai SW, Hahn HT (1980) Introduction to composite materials. Technomic Publishing Co., Inc., Lancaster, Pennsylvania

9. Jacquemin F, Fréour S, Guillén R (2005) J Reinf Plast Comp $24: 485$

10. Jacquemin F, Fréour S, Guillén R (2004) A self-consistent approach for transient hygroscopic stresses and moisture expansion coefficients of fiber-reinforced composites, Proc. ECCM 11, 31st of May to 3rd of June 2004, Rhodes, Greece

11. Morawiec A (1989) Phys Stat Sol b 154:535

12. Aleksandrov KS, Aisenberg LA (1966) Dokl Akad Nauk SSSR 167:1028

13. Matthies S, Humbert M (1993) Phys Stat Sol b 177: K47

14. Matthies S, Humbert M, Schuman Ch (1994) Phys Stat Sol b 186:K41

15. Hill R (1967) J Mech Phys Solids 15:79

16. Kocks UF, Tomé CN, Wenk HR (1998) Texture and anisotropy. Cambridge University Press

17. Sprauel JM, Castex L (1991). First European powder diffraction international conference on X-Ray stress analysis, Munich

18. Morris PR (1970) Int J Eng Sci 8L:49

19. Asaro RJ, Barnett DM (1975) J Mech Phys Sol 23:77

20. Soden PD, Hinton MJ, Kaddour AS (1988) Compos Sci Technol 58:1011

21. Tsai SW (1987) Composite design, 3rd edn. Think Composites, Dayton, USA

22. Loos AC, Springer GS (1981) Moisture absorption of graphite-epoxy composition immersed in liquids and in humid air, Environmental effects on composite materials, p 34

23. Jacquemin F, Vautrin A (2002) Compos Struct 58:1 